\title{
PENINGKATAN KEMAMPUAN KOMUNIKASI DAN KERJASAMA MELALUI KKN POSDAYA DI UNIVERSITAS MATHLA'UL ANWAR BANTEN
}

\author{
Asep Sujana', Ika Meika²
}

\begin{abstract}
Abstrak: Universitas Mathla'ul Anwar (Unma) Banten merupakan salah satu Universitas yang terletak di Kabupaten Pandeglang dari tahun ke tahun berusaha meningkatkan kualitas dalam pengabdian kepada masyarakat. Salah satu kegiatan yang sudah berjalan adalah Kuliah Kerja Nyata (KKN) Posdaya. Sampai saat ini kegiatan KKN sudah berjalan, namun secara peningkatan kapasitas untuk menjadi mahasiswa yang siap terjun di masyarakat masih perlu ditingkatkan. Tujuan adanya kegiatan KKN di Unma, yaitu untuk pengintegrasian dari pendidikan dan pengajaran, penelitian dan pengabdian kepada masyarakat oleh mahasiswa secara pragmatis, berdimensi luas melalui pendekatan interdisipliner, komprehensif, dan lintas sektoral. Dengan adanya Keigatan KKN ini, diharapkan mahasiswa menjadi bagian masyarakat yang dapat berkontribusi langsung dalam membantu permasalahan yang ada di masyarakat. Metode pendekatan program peningkatan kapasitas komunikasi dan kerjasama adalah menggunakan metode PALS (Participatory Action Learning System).
\end{abstract}

Kata Kunci: KKN Posdaya, Kemampuan Komunikasi, Kemampuan Kerjasama.

\section{The Improvement of Communication and Cooperation Ability Through KKN Posdaya in Mathla'ul Anwar University, Banten}

\begin{abstract}
Universitas Mathla'ul Anwar Banten is one of the university which is located in Pandeglang Regency. It always tries to improve the quality in the service for the society. One of the activities in Mathla'ul Anwar University that has already been done is KKN Posdaya Program. The KKN activity has already been done well, however it needs some improvements in the capacity of the students who are ready to involve themselves in the society. The KKN activity in Mathla'ul Anwar University aims to integrate the education and teaching, research and community service by the students pragmatically, comprehensive dimension through an interdisciplinary approach, comprehensive, and cross-sector. By doing the KKN Activity, it is hoped that the students will be a part of the society that can contribute directly to help the problems in the society. The Approach method for the improvement capacity program of communication and cooperation uses PALS (Participatory Action Learning System) method.
\end{abstract}

Keywords: KKN Posdaya, Communication Ability, Cooperation Ability

\section{PENDAHULUAN}

Universitas Mathla'ul Anwar (Unma) Banten adalah lembaga pendidikan tinggi swasta di Banten. Sebagai sebuah perguruan tinggi yang sedang berkembang, Unma Banten saat ini diperkuat oleh dosen-dosen muda yang potensial dan didukung oleh minat masyarakat. Identitas ideologis Unma Banten sebagai anak kandung dari gerakan masyarakat sipil Islam di

\footnotetext{
${ }^{1}$ Program Studi Matematika, Fakultas Keguruan dan Ilmu Pendidikan Universitas Mathla'ul Anwar Banten; email: ikasep123@gmail.com.

2 Program Studi Matematika, Fakultas Keguruan dan Ilmu Pendidikan Universitas Mathla'ul Anwar Banten; email: ikameika@yahoo.co.id.
} 
Indonesia, Mathla'ul Anwar, menjadi kekuatan tersendiri bagi Unma Banten untuk mengembangkan diri, memperkuat jaringan kerjasama dengan pihak lain, serta untuk membangun hubungan yang harmonis dengan masyarakat. Dalam usianya yang muda pula kampus Unma Banten telah dilengkapi dengan infrastruktur pendidikan yang memadai, dengan menempati lahan utama seluas kurang lebih 15 hektar, dengan sarana dan prasarana pendidikan yang dilengkapi dengan fasilitas pendidikan, laboratorium penelitian, sarana olahraga, dan kegiatan kemahasiswaan. Karena itu, Unma Banten menjadi tempat yang kondusif untuk penguatan kegiatan akademik, termasuk di bidang penelitian dan pengabdian masyarakat. Saat ini Unma Banten telah memiliki 10 Fakultas, diantaranya Fakultas Agama, Keguruan dan Ilmu Pendidikan, FISIP, Hukum, MIPA, Kesehatan, Komputer, Ekonomi, Teknik dan Pertanian.

Untuk menjawab tantangan dalam dunia kerja yang persaingannya terus meningkat, yang salah satunya adalah lulusan dituntut untuk dapat berkomunikasi dan bekerjasama dengan pihak lain dan ini tertuang dalam misi Unma Banten. Untuk menggali kemampuan tersebut, salah program rutin yang diselenggarakan adalah Kuliah Kerja Nyata (KKN) di bawah koordinasi Lembaga Penelitian Pengabdian, dan Pengembangan Masyarakat (LP3M).

Dalam panduan KKN Tematik Unma Banten (2013: 2) dijelaskan bahwa KKN adalah wadah pembelajaran yang diharapkan dapat membuka akses komunikasi dan intergrasi Civitas Akademika ke dalam masyarakat dengan titik tumpu pada bidang keagamaan, pendidikan, kesehatan, ekonomi (kewirausahaan) dan lingkungan sebagai basis kompetensi perguruan tinggi dengan memberikan respon terhadap kuatnya tekanan globalisasi terhadap lapisan masyarakat. Dalam pelaksanaan KKN dilaksanakan secara bersama oleh seluruh fakultas, sehingga peserta yang terlibat dalam KKN ini sangat beragam sesuai dengan keilmuannya. Posdaya adalah program pemberdayaan yang menitikberatkan manusia (pribadi atau individu) dan keluarga sebagai sentral pembangunan yang berkesinambungan.

Salah satu tantangan terbesar mahasiswa setelah mereka lulus adalah masih sulitnya mereka dapat menjalin kerjasama dengan stakeholder yang ada di masyarakat, padahal mereka hidup dalam masyarakat. Untuk itulah harus ada kegiatan yang mendorong bagaimana mahasiswa agar dapat berinteraksi langsung dengan masyarakat dan menjalin kerjasama dalam sebuah program yang dirancag secara bersama. KKN adalah kegiatan yang dirancang untuh hal tersebut, dengan harapan nantinya mahasiswa setelah lulus sudah memiliki bekal yang cukup dalam hal bekerjasama dan merancang kegiatan di masyarakat ataupun dalam dunia kerja.

Nurfitriah (2006: 78) menjelaskan bahwa kerjasama merupakan pencapaian kematangan dalam hubungan sosial, dapat juga diartikan sebagai proses belajar untuk menyesuaikan diri terhadap norma kelompok, moral, dan tradisi, meleburkan diri menjadi suatu kesatuan dan saling berkomunikasi dan bekerja sama. Saat ini unma telah memiliki beberapa desa binaan yang tersebar di kabupaten Pandeglang dan Lebak. Di desa binaan tersebutlah didorong untuk membentuk Pos Pemberdayaan Keluarga (Posdaya) yang menjadi wadah semua kegiatan KKN. Masing-masing kelompok KKN yang 
terdiri dari berbagai fakultas tersebut bersinergi dengan masyarakat untuk menyusun, merencanakan dan melaksanakan program yang di sesuaikan dengan masalah dan potensi dari desa-desa binaan tersebut.

\section{METODE PELAKSANAAN}

LP3M Unma Banten telah menetapkan sejumlah sasaran kegiatan KKN Tematik berbasis masjid dengan program Pos Pemberdayaan Keluarga (Posdaya) tahun 2015, salah satunya adalah masyarakat di Desa Curuglemo Kecamatan Manadalawangi.

Pelaksanaan kegiatan KKN Universitas Mathla'ul Anwar dengan program Pos Pemberdayaan Keluarga (Posdaya) Tahun 2015 di Desa Curuglemo Kecamatan Mandalawangi dilakukan dengan kerangka pemecahan masalah sebagai berikut: 1) Koordinasi dengan stakeholder terkait; 2) Musyawarah Pembentukan Posdaya; 3) Identifikasi potensi dan masalah desa; 4) Perencanaan Program Posdaya; 5) Menjalin kerjasama dengan semua stakeholder; 6) Pelaksanaan Program; dan 7) Monitoring dan evaluasi program.

Pelaksanaan program ini menggunakan metoda PALS dengan beberapa tahapan, yaitu: 1) Tahap awareness; 2) Tahap peningkatan kapasitas dan magang; 3) Pelembagaan.

\section{HASIL DAN PEMBAHASAN}

Kegiatan dalam KKN dengan program Posdaya di Desa Curuglemo Kecamatan Mandalawangi dilakukan dengan tujuh tahap seperti dipaparkan sebagai berikut.

Pertama, koordinasi dengan stakeholder terkait. Pada kegiatan ini mahasiswa bersama dosen pembimbing lapangan melakukan koordinasi dengan pihak kecamatan, desa/kelurahan, RT/RW dan tokoh masyarakat setempat. Kegiatan ini dimaksudkan untuk memberikan pemaparan dan gambaran terkait rencana kegiatan KKN dan memohon ijin untuk pelaksanaan kegiatan sesuai dengan jadwal yang di rencanakan. Kegiatan ini juga dilakukan dengan acara ceremonial penerimaan mahasiswa KKN baik ditingkat kecamatan ataupun ditingkat desa.

Kedua, identifikasi potensi dan masalah desa. Pada kegiatan identifikasi dan masalah yang ada di desa sasaran dilaksanakan bersama masyarakat, kegiatan ini dimaksudkan untuk menggali potensi dan masalah apa saja yang terdapat di desa sasaran. Beberapa hal yang menjadi di desa Curuglemo ditinjau dari tiga aspek yaitu aspek pendidikan, kesehatan dan ekonomi.

Ketiga, musyawarah Pembentukan Posdaya. Untuk keberlangsungan program-program dibutuhkan sebuah wadah yang lahir dari komponen masyarakat itu sendiri. Posdaya adalah wadah untuk melaksanakan semua program-program tersebut. Dalam pembentukannya menggunakan asas musyawarah mufakat, mengedepankan kebersamaan, dengan menggunakan 
prinsip semuanya berasal dari masyarakat, oleh masyarakat dan untuk masyarakat.

Keempat, perencanaan Program Posdaya. Setelah terbentuknya posdaya dirancanglah program-program kegiatan yang di sesuaikan dengan potensi dan masalah yang ditinjau dari tiga aspek pendidikan, kesehatan dan ekonomi.

Kelima, menjalin kerjasama dengan semua stakeholder. Untuk mengoptimalkan pelaksanaan program, mahasiswa bersama Posdaya menjalin kejasama dengan beberapa pemangku kepentingan, diantaranya puskesmas setempat dan lembaga amil zakat (LAZ) Harfa Pandeglang dalam mengoptimalkan pelaksanaan program dalam aspek kesehatan.

Keenam, pelaksanaan program. Dalam tahapan pelaksanaan, semua elemen terlibat untuk melaksanakan kegiatan yang telah dirancang sebelumnya. Dalam aspek pendidikan, kegiatan yang dilaksanakan adalah mahasiswa terlibat langsung dalam memberikan pembinaan dan pengarahan terhadap anak yang putus sekolah agar mau sekolah lagi, selain itu mereka juga terjun langsung dalam memberikan pembelajaran di SD dan SMP yang ada di desa Curuglemo sesuai dengan keilmuan yang mereka miliki. Pada aspek kesehatan, kegiatan yang dilaksanakan adalah pemicuan CLTS yang bekerja sama dengan LAZ Harfa Pandeglang. Pemicuan ini bertujuan guna mengajak masyarakat membangun fasilitas MCK dan menggunakannya dari keinginan mereka sendiri. Karena di Desa Curuglemo masih banyak masyarakat yang membuang hajat bukan pada tempatnya.

Ketujuh, monitoring dan evaluasi program. Kegiatan ini adalah kegiatan akhir dari semua rangkaian kegiatan dan dilaksanakan secara berkala. Agar semua rancangan kegiatan dapat terus berjalan dan ada perbaikan-perbaikan dalam kegiatan berikutnya.

Dampak dan manfaat pelaksanaan kegiatan pengabdian kepada masyarakat untuk KKN dengan program Posdaya adalah: Pertama, meningkatnya wawasan dan skill mahasiswa dalam memahami kehidupan di masyarakat, sehingga berdampak pada peningkatan kapasitas dan kemampuan dalam menjalin komunikasi dan membangun kerjasama dalam masyarakat. Kedua, dengan adanya program KKN Posdaya, pengetahuan dan kemampuan mahasiswa semakin terasah sehingga kedepannya mampu menghasilkan jiwa-jiwa yang siap terjun dalam masyarakat.

\section{KESIMPULAN}

Kegiatan KKN Posdaya di Universitas Mathla'ul Anwar Banten fokus pada peningkatan kapasitas mahasiswa dalam memahami, menguasai dalam mejalin komunikasi dan membangun kerjasama dengan semua pihak. Ini menjadi modal besar ketika mahasiswa terjun langsung di masyarakat setelah mereka lulus kuliah. 


\section{REFERENSI}

Nurfitriah. (2006). Program bimbingan sosial pribadi untuk meningkatkan keterampilan sosial siswa. Skripsi Jurusan PPB FIP UPI Bandung: Tidak Diterbitkan.

Syihabudin, A. et.al. (2013). Panduan pelaksanaan KKN tematik Universitas Mathla'ul Anwar 2013 posdaya berbasis masjid. Pandeglang: LP3M UNMA Banten.

\section{UCAPAN TERIMAKASIH}

1. Universitas Mathla'ul Anwar Banten untuk dukungan baik finansial dan fasilitas sehingga kegiatan KKN di Desa Curuglemo berjalan sesuai rencana.

2. LP3M Universitas Mathla'ul Anwar Banten.

3. Fakultas Keguruan dan IImu Pendidikan Universitas Mathla'ul Anwar Banten. 